\title{
Exploring Secondary Metabolites in Coffee and Tea Food Wastes
}

\author{
Mariana Cecilia Grohar*, Barbara Gacnik, Maja Mikulic Petkovsek (), Metka Hudina (1) and Robert Veberic (1)
}

check for

updates

Citation: Grohar, M.C.; Gacnik, B.; Mikulic Petkovsek, M.; Hudina, M.; Veberic, R. Exploring Secondary Metabolites in Coffee and Tea Food Wastes. Horticulturae 2021, 7, 443. https://doi.org/10.3390/ horticulturae7110443

Academic Editors: Riccardo Testa, Giuseppina Migliore, Giorgio Schifani and József Tóth

Received: 29 September 2021

Accepted: 22 October 2021

Published: 1 November 2021

Publisher's Note: MDPI stays neutral with regard to jurisdictional claims in published maps and institutional affiliations.

Copyright: (c) 2021 by the authors. Licensee MDPI, Basel, Switzerland. This article is an open access article distributed under the terms and conditions of the Creative Commons Attribution (CC BY) license (https:// creativecommons.org/licenses/by/ $4.0 /)$.
Biotechnical Faculty, University of Ljubljana, Jamnikarjeva 101, 1000 Ljubljana, Slovenia; www.gacnik@gmail.com (B.G.); maja.mikulic-petkovsek@bf.uni-lj.si (M.M.P.); metka.hudina@bf.uni-lj.si (M.H.); robert.veberic@bf.uni-lj.si (R.V.)

* Correspondence: marianacecilia.grohar@bf.uni-lj.si

\begin{abstract}
Coffee and tea are popular beverages worldwide, and therefore generate large amounts of waste. Here we describe the caffeine content and phenolic profile in three types of teas and coffees, and how they vary with two successive extractions. Although the first extraction was far more efficient than the second, green tea also showed a high content of flavanols in the second extraction, as did mate tea for phenolic acids. Black tea could also be a good option since caffeine content was highest in both extractions. Water also proved to be the most effective solvent in almost all cases, which represent a major benefit for urban horticulture, as it is a simple extraction method from an easily accessible source. Coffee and tea residues are a rich source of caffeine and phenolic compounds that could potentially be used as alternatives to conventional pesticides.
\end{abstract}

Keywords: caffeine; phenolic compounds; solvents; second extraction

\section{Introduction}

Secondary metabolites intervene mainly in ecological processes, acquired along the evolution, such as UV protection, interaction with pollinators, and protection against pathogens [1,2]. Among secondary metabolites, alkaloids and phenolic compounds are involved in plant defense system against pests, radiation, and stress [3-5].

Caffeine (1,3,7-trimethylxanthine) is one of the most frequent purine alkaloids in plants. Pure caffeine crystals are odorless, bitter and soluble in water, though solubility increases with temperature [6]. It is stored mainly in young leaves and flowers, as they are particularly sensitive to pathogen attack [6], but also in other organs [7-10]. For this reason, it was tested in many species of agronomic importance [11]. Caffeine is also known for its allelopathic effects, as fallen leaves above coffee shrubs inhibit the development of competitive species by preventing access to water and nutrients [12], therefore inhibiting root growth [13] and chlorophyll content [14]. The caffeine content of coffee beans varies from $0.4 \%$ to $2.4 \%$ of dry weight, depending on the species [11]. In mate leaves, caffeine is the most abundant xanthine, about 1-2\% of dry weight [15]. Many analyses focused on commercial brands of coffee and tea, to evaluate and compare their contents [16-18].

Among phenolic compounds, flavonoids are the target of modern research due to their antioxidant activity and potential medicinal use in human health [19]. They are also known for their role in plant response to biotic and abiotic stress. Tea is especially known as an important source of polyphenols, mainly flavonoids and phenolic acids [14].

Nowadays, traditional pesticides are being questioned and research is focused on finding effective, environment-friendly, and easily accessible alternatives to replace them. Considering this fact, many infusions consumed worldwide, such as green and black tea (Camellia sinensis (L.) Kuntze), mate tea (Ilex paraguariensis A.St.-Hil.), and coffee (Coffea L. spp.), could be potential alternative sources, since they are easily accessible to any consumer and generate large amounts of waste [20]. Due to its bioactive properties, numerous applications for coffee grounds have already been considered [21,22] but rarely 
in urban horticulture. This becomes important in the context of the circular economy of food, which focuses on the reuse of food waste as fertilizers or biofuel and promotes resources' efficient use and urban sustainability at macro- and micro- levels [23,24].

The aim of this work is to extract and analyze the content of caffeine and phenolic compounds in different natural sources (green tea, black tea, mate tea, and three commercial brands of coffee) using HPLC/MS. Additionally, we analyze how they vary with different solvents (distilled water, methanol, and methanol:water) in successive extractions, in order to determine if reused tea or coffee residues could be potential pesticides. This aim addresses two challenges that the world is facing today: (1) the disposal of human waste and (2) the search for easily-accessible, environmentally friendly pesticides.

\section{Materials and Methods}

The entire study was completed at the Chair for Fruit Growing, Viticulture, and Vegetable Growing (Biotechnical Faculty, University of Ljubljana, Ljubljana, Slovenia).

\subsection{Plant Material}

Commercial samples of teas were purchased from local stores in Ljubljana, Slovenia. We included three types of tea: green tea (1001 cvet), black tea (1001 cvet), and mate tea (Playadito). In addition, three types of coffees were selected with supposedly different strengths, here referred to as 'ground' (standard coffee-Barcaffe), 'intense' (Death Wish, advertised as 'World's strongest coffee'), and 'instant' coffee (Nescafe).

\subsection{Extraction of Caffeine and Phenolic Compounds}

Three solvents were considered in this study: water (W), 100\% methanol (M), and water:methanol mix 1:1 (W:M). Methanol is the standard solvent for phenolic compounds' extraction in laboratory research and industrial production [3]. However, as homemade infusions are prepared with water, we included it in the analysis to compare the results with a standard solvent. We also tested a 1:1 water:methanol mix, since the dilution of alcoholic solvents can improve the extraction of some phenolic compounds [25,26].

For the extractions with water, $1.5 \mathrm{~g}$ of the content of different tea bags or $5 \mathrm{~g}$ of coffee were immersed in $100 \mathrm{~mL}$ of double distilled water boiled at $100{ }^{\circ} \mathrm{C}$ and allowed to stand at room temperature for $30 \mathrm{~min}$. During this period of time, the solution was not heated, so that the temperature slowly decreased, simulating the domestic preparation of infusions. For the other two solvents, $0.5 \mathrm{~g}$ of the content of different tea bags or $1.5 \mathrm{~g}$ of coffee were immersed in $25 \mathrm{~mL}$ of methanol (Sigma-Aldrich, Steinheim, Germany) or 1:1 double distilled water:methanol mix, both solvents at room temperature. Then, they were placed in an ultrasonic bath for $30 \mathrm{~min}$. Six samples were prepared for each treatment. Then, all samples were centrifuged at $8000 \times \mathrm{g} \mathrm{rpm}$ and $4{ }^{\circ} \mathrm{C}$ for $7 \mathrm{~min}$. The supernatants were then filtered with $0.2-\mu \mathrm{m}$ Chromafil@AO-20/25 polyamide filters.

Since we are looking for reusable, easily-accessible sources of caffeine and phenolic contents, we evaluated the content caffeine and phenolic compounds in reboiled coffee grounds and tea bags. After the first extraction, tea bags and coffee grounds were dried and extracted again following the same method as for the first extraction. Instant coffee was not evaluated in the second extraction because the powder dissolved completely in first extraction with water, and little grounds remained with methanol and water:methanol.

\subsection{Analysis with HPLC-MS}

The extracted samples were then analyzed with an Accela HPLC system (Thermo Fisher Scientific, Waltham, MA, USA) with a diode array detector at $240 \mathrm{~nm}$ for caffeine, flavanols at $280 \mathrm{~nm}$, flavonols at $350 \mathrm{~nm}$, and phenolic acids at $310 \mathrm{~nm}$. A Phenomenex HPLC column C18 $(150 \times 4.6 \mathrm{~mm}$, Gemini $3 \mu \mathrm{m})$ was used at $25^{\circ} \mathrm{C}$, following the method of [27]. Phenolics were identified by comparing their UV-Vis spectra and retention times with standards and also confirmed using a mass spectrometer (Thermo Fisher Scientific, LCQ Deca XP MAX) with an electrospray interface (ESI) operating in negative ion mode. 
Full scan data-dependent MSn scanning from $m / z$ 115-1400 was performed. All conditions on the mass spectrometer were the same as reported by [28].

The results of the caffeine content are expressed in $\mathrm{mg}$ of caffeine/g of sample, and for phenolic compounds in $\mathrm{mg}$ of compound $/ \mathrm{kg}$ of sample. It was calculated based on standard calibration curve $\left(y=119,044.23 x, R^{2}=1.00\right)$.

\subsection{Chemicals}

HPLC grade methanol for the extraction of the phenolics was purchased from SigmaAldrich (Steinheim, Germany). For the mobile phases, we used HPLC-MS grade acetonitrile and formic acid from Fluka Chemie (Buch, Switzerland). The following standards were used for quantification phenolic compounds: Fluka Chemie (Buch, Switzerland): caffeine, quercetin-3-glucoside, quercetin-3-galactoside, quercetin-3-rhamnoside, (-)-epicatechin, gallic acid, procyanidin B1, $p$-coumaric acid and kaempferol-3-glucoside; Sigma-Aldrich: quercetin-3-rutinoside, ferulic acid, 3-caffeoylquinic acid and 5-caffeoylquinic acid; Roth (Karlsruhe, Germany): (+)-catechin; Extrasynthese (Genay, France): isorhamnetin-3glucoside; Apin Chemicals (Abingdon, UK): myricetin-3-rhamnoside. The water for phenolic compounds extraction and for mobile phases was double distilled and purified with a Mili-Q Millipore system (Merck Millipore, Billerica, MA, USA).

\subsection{Statistical Analysis}

Analysis of variance (ANOVA) was performed using R-commander 64 3.3.3, along with multiple comparison Duncan test for statistical significance $(\alpha \leq 0.05)$ between solvents of every product and extraction.

\section{Results}

\subsection{Caffeine Content \\ 3.1.1. Teas}

The caffeine content showed differences between tea types and solvents (Figure 1A and Table S1). For green tea, the water and water:methanol mix extracted higher amounts of caffeine than methanol in the first extraction: $16.6 \mathrm{mg} / \mathrm{g}$ in water, $16 \mathrm{mg} / \mathrm{g}$ in water:methanol mix, and $13 \mathrm{mg} / \mathrm{g}$ for methanol. In the second extraction, caffeine content decreased by $87 \%$ in water, $81 \%$ in methanol, and $89 \%$ in water:methanol mix.

Black tea showed a high caffeine content in water and water:methanol mix first extractions: $26.8 \mathrm{mg} / \mathrm{g}$ and $30.9 \mathrm{mg} / \mathrm{g}$, respectively. In both solvents, the first extraction was more efficient than the second, as caffeine content decreased by 54 and $67 \%$, respectively. The first extraction with methanol extracted significantly less caffeine than the other solvents: $9.9 \mathrm{mg} / \mathrm{g}$, decreasing by $67 \%$ in the second extraction.

Mate tea has the lowest caffeine content for the first extraction, regardless of the solvent. Water was more efficient than methanol and water:methanol mix, with 8.1, 6.2, and $6.5 \mathrm{mg} / \mathrm{g}$, respectively, decreasing by $74 \%$ in water, $81 \%$ in methanol, and $41 \%$ in water:methanol mix. 
A
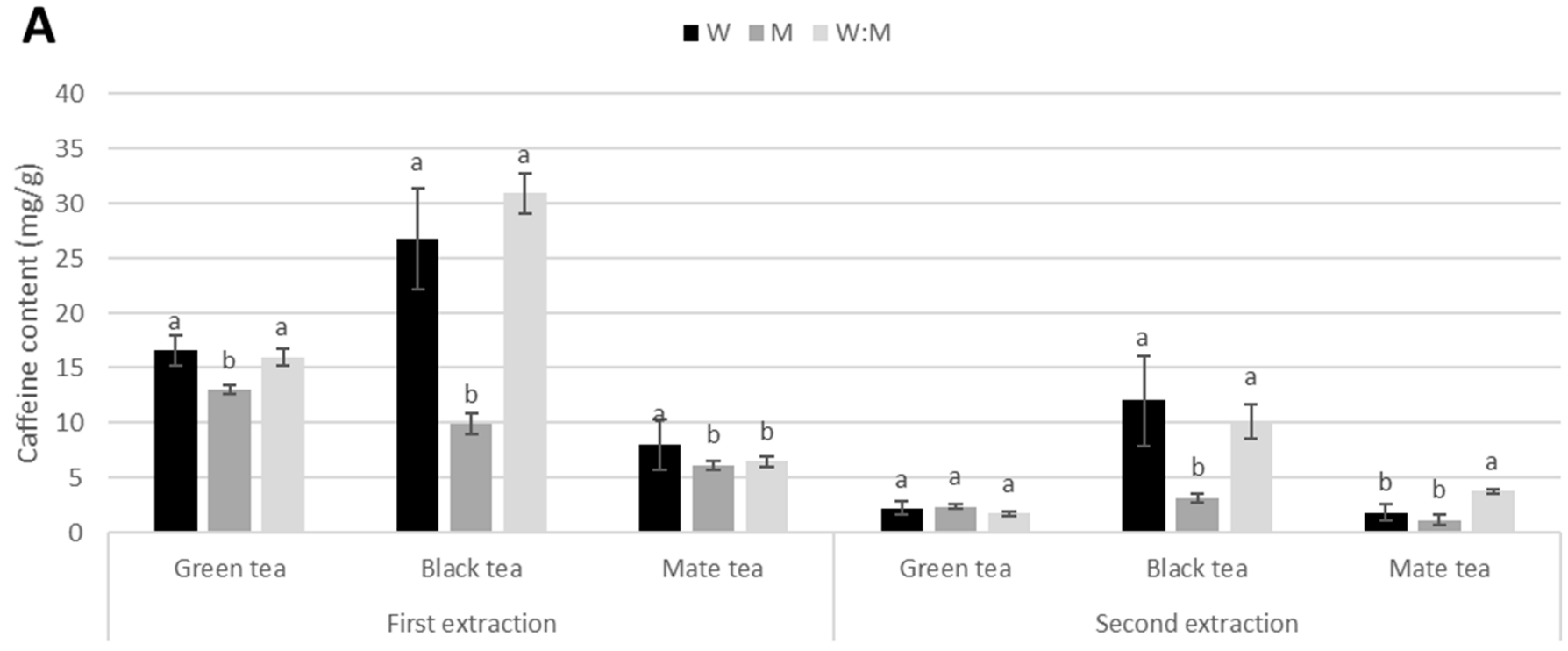

B

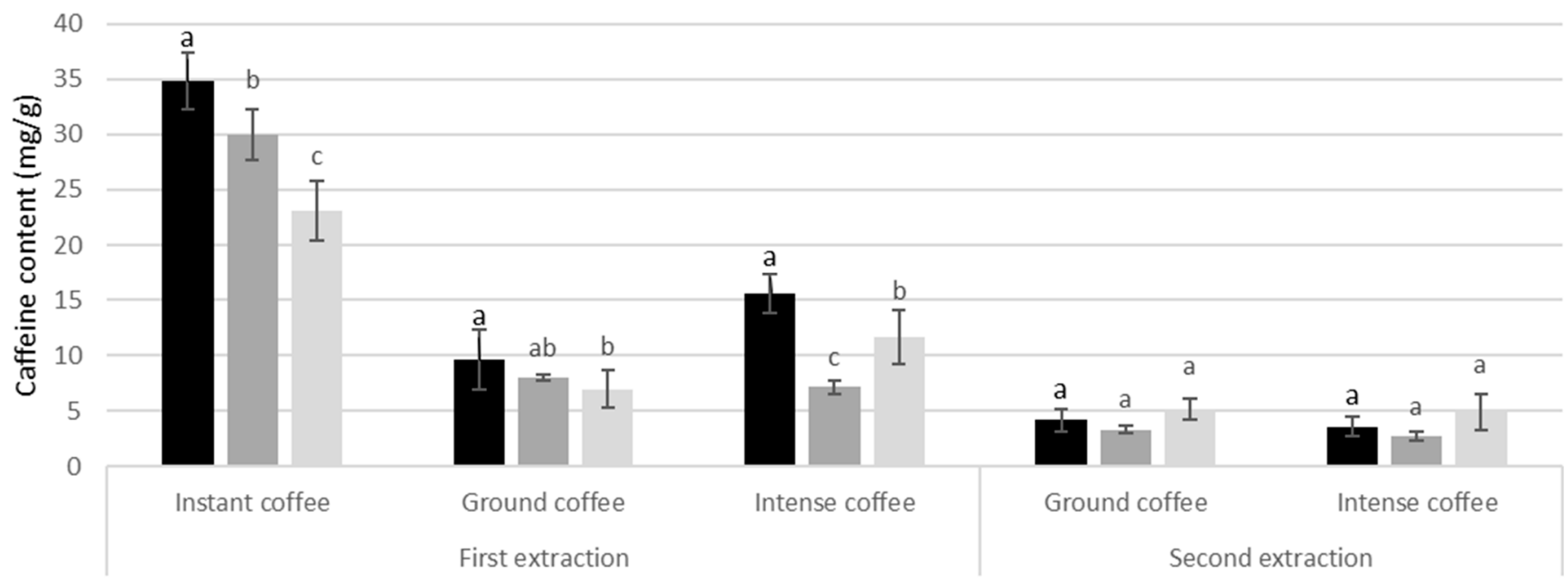

- $\mathrm{W} \backsim \mathrm{M} \square \mathrm{W}: \mathrm{M}$

Figure 1. Caffeine content (mg/g) during first and second extraction with different solvents (W: water, M: 100\% methanol; W:M: water:methanol mix) in commercial brands of (A) teas and (B) coffees. Different letters indicate statistical significance $(p \leq 0.05)$ in caffeine content between solvents.

\subsubsection{Coffees}

Among coffees, caffeine content showed different trends than teas (Figure 1B and Table S1). The highest caffeine content for the first extraction was found in instant coffee, $34.8 \mathrm{mg} / \mathrm{g}$ in water, $30 \mathrm{mg} / \mathrm{g}$ in methanol, and $23.1 \mathrm{mg} / \mathrm{g}$ in water:methanol mix. However, there was no waste available for the second extraction.

For ground coffee, the caffeine content in the first extraction was the lowest among all coffees, being from 3 to $5.5 \%$ higher in water than in the water:methanol mix $(4.7-12.7 \mathrm{mg} / \mathrm{g}$ and $5.2-9.4 \mathrm{mg} / \mathrm{g}$, respectively), while the methanol extracts show intermediate values with no significant difference from the other two. The second extraction shows lower caffeine content than the first extraction, with a decrease of $50 \%$ for water, $59 \%$ for methanol, and $20 \%$ for water:methanol mix. However, the extracted caffeine content is similar for all solvents. 
Finally, for intense coffee, water extracted the significantly highest caffeine content, with $15.6 \mathrm{mg} / \mathrm{g}$ of caffeine, followed by water:methanol mix and methanol, with 11.6 and $7.2 \mathrm{mg} / \mathrm{g}$ of caffeine, respectively. In the second extraction, lower but similar amounts of caffeine were extracted with all solvents, decreasing by $77 \%$ for water, $63 \%$ for methanol, and $54 \%$ for the water:methanol mix.

\subsection{Phenolic Profile}

Among phenolic acids, most of the identified compounds were hydroxycinnamic acids, except for 5-O-galloylquinic acid, which is a hydroxybenzoic acid (Tables 1 and 2).

Table 1. Identification of phenolic compounds in green, black, and mate tea in negative ionization with HPLC-MS and $\mathrm{MS}^{2} / \mathrm{MS}^{3}$.

\begin{tabular}{|c|c|c|c|c|c|c|}
\hline & $\begin{array}{c}{[\mathrm{M}-\mathbf{H}]^{-}} \\
(\mathrm{m} / \mathrm{z})\end{array}$ & $\begin{array}{l}\mathrm{MS}^{2} \\
(\mathrm{~m} / \mathrm{z})\end{array}$ & $\begin{array}{l}\mathrm{MS}^{3} \\
(\mathrm{~m} / \mathrm{z})\end{array}$ & Green Tea & Black Tea & Mate Tea \\
\hline \multicolumn{7}{|l|}{ FLAVANOLS } \\
\hline Procyanidin dimer 1 & 577 & $451,425,407,289$ & & $x$ & & \\
\hline Procyanidin dimer 2 & 577 & $451,425,407,289$ & & $\mathrm{x}$ & & \\
\hline Procyanidin dimer 3 & 577 & $451,425,407,289$ & & $x$ & & \\
\hline Epigallocatechin 1 & 305 & $261,221,219,179$ & & $x$ & $x$ & \\
\hline Epigallocatechin 2 & 305 & $261,221,219,179$ & & $x$ & & \\
\hline Catechin & 289 & 245 & & & $x$ & \\
\hline Gallocatechin & 305 & $261,221,219,179$ & & $x$ & $x$ & \\
\hline Gallocatechin gallate & 457 & $331,305,169$ & & & $x$ & \\
\hline Epigallocatechin gallate 1 & 457 & $331,305,169$ & & $x$ & $x$ & \\
\hline Epigallocatechin gallate 2 & 457 & $331,305,169$ & & $x$ & & \\
\hline Epigallocatechin gallate 3 & 457 & $331,305,169$ & & $x$ & & \\
\hline Epigallocatechin gallate 4 & 457 & $331,305,169$ & & $x$ & & \\
\hline Epicatechin & 289 & 245 & & & $x$ & \\
\hline Epicatechin gallate 1 & 441 & $289,169,331$ & & $x$ & $x$ & \\
\hline Epicatechin gallate 2 & 441 & $289,169,331$ & & $\mathrm{x}$ & $x$ & \\
\hline Epicatechin gallate 3 & 441 & $289,169,331$ & & $x$ & & \\
\hline Theaflavine & 563 & $545,519,425,407,241$ & & $x$ & $x$ & \\
\hline Theaflavine-3,3-digallate & 867 & $697,715,527,483,389$ & & & $x$ & \\
\hline Theaflavine-3-gallate & 715 & $527,545,577,507$ & & & $x$ & \\
\hline FLAVONOLS & & & & $x$ & & \\
\hline Myricetin hexoside 1 & 479 & 317 & & $x$ & $x$ & \\
\hline Myricetin hexoside 2 & 479 & 317 & & $x$ & $x$ & \\
\hline $\begin{array}{l}\text { Quercetin hexoside } \\
\text { rhamnoside hexoside }\end{array}$ & 771 & 463 & 301 & $x$ & & \\
\hline $\begin{array}{l}\text { Quercetin rhamnoside } \\
\text { hexoside }\end{array}$ & 609 & 463 & 301 & $x$ & $x$ & \\
\hline $\begin{array}{l}\text { Quercetin rhamnosyl hexoside } \\
\text { dirhamnoside }\end{array}$ & 901 & 755 & 609,301 & & $x$ & \\
\hline $\begin{array}{l}\text { Kaempferol rhamnosyl } \\
\text { hexoside dirhamnoside }\end{array}$ & 885 & 739 & 431,285 & & $x$ & \\
\hline Kaempferol acetylhexoside & 489 & 285 & & & $x$ & \\
\hline Quercetin-3-rutinoside & 609 & 301 & & $x$ & $x$ & $x$ \\
\hline Quercetin-3-galactoside & 463 & 301 & & $x$ & $x$ & \\
\hline Quercetin-3-glucoside & 463 & 301 & & $\mathrm{x}$ & $x$ & $\mathrm{x}$ \\
\hline Kaempferol-3-galactoside & 447 & 285 & & & $x$ & \\
\hline Kaempferol-3-glucoside & 447 & 285 & & & $x$ & \\
\hline Kaempferol-3-rutinoside & 593 & 285 & & $x$ & $x$ & $x$ \\
\hline $\begin{array}{l}\text { Kaempferol hexoside } \\
\text { rhamnoside }\end{array}$ & 593 & 431 & 285 & & $x$ & \\
\hline
\end{tabular}


Table 1. Cont.

\begin{tabular}{|c|c|c|c|c|c|c|}
\hline & $\begin{array}{c}{[\mathbf{M}-\mathbf{H}]^{-}} \\
\quad(m / z)\end{array}$ & $\begin{array}{l}\mathbf{M S}^{2} \\
(\mathrm{~m} / \mathrm{z})\end{array}$ & $\begin{array}{l}\mathrm{MS}^{3} \\
(\mathrm{~m} / \mathrm{z})\end{array}$ & Green Tea & Black Tea & Mate Tea \\
\hline Isorhamnetin-3-rutinoside & 623 & 315 & & & & $x$ \\
\hline PHENOLIC ACIDS & & & & $x$ & & \\
\hline 3-p-Coumaroylquinic acid & 337 & 163 & & $X$ & $X$ & $x$ \\
\hline 4- $p$-Coumaroylquinic acid & 337 & $173,163,191$ & & & $x$ & $X$ \\
\hline 5- $p$-Coumaroylquinic acid & 337 & $191,173,163$ & & & $x$ & \\
\hline 3-feruloylquinic acid & 367 & 193,134 & & & & $x$ \\
\hline 4-feruloylquinic acid & 367 & 173,191 & & & & $x$ \\
\hline 3-Caffeoylquinic acid 1 & 353 & $179,191,173$ & & $x$ & $x$ & $X$ \\
\hline 3-Caffeoylquinic acid 2 & 353 & $179,191,173$ & & & $x$ & \\
\hline 4-Caffeoylquinic acid & 353 & 173,179 & & $X$ & $X$ & $x$ \\
\hline 5-Caffeoylquinic acid 1 & 353 & 191,179 & & $x$ & $x$ & $x$ \\
\hline 5-Caffeoylquinic acid 2 & 353 & 191,179 & & & $x$ & $x$ \\
\hline 5-Galloylquinic acid & 343 & $191,169,125$ & & $x$ & & \\
\hline Gallic acid & 169 & 125 & & $x$ & & \\
\hline Dicaffeoylquinic acid 1 & 515 & 353 & 179,191 & & & $x$ \\
\hline Dicaffeoylquinic acid 2 & 515 & 353 & 173,179 & & & $x$ \\
\hline Dicaffeoylquinic acid 3 & 515 & 353 & 179,191 & & & $x$ \\
\hline Dicaffeoylquinic acid 4 & 515 & 353 & 191,179 & & & $x$ \\
\hline
\end{tabular}

Table 2. Identification of phenolic compounds in coffees in negative ionization with HPLC-MS and MS ${ }^{2} \mathrm{MS}^{3}$.

\begin{tabular}{|c|c|c|c|c|c|c|}
\hline & $\begin{array}{c}{[\mathbf{M}-\mathbf{H}]^{-}} \\
\quad(\mathrm{m} / \mathrm{z})\end{array}$ & $\begin{array}{l}\mathrm{MS}^{2} \\
(\mathrm{~m} / z)\end{array}$ & $\begin{array}{l}\mathrm{MS}^{3} \\
(\mathrm{~m} / z)\end{array}$ & $\begin{array}{l}\text { Instant } \\
\text { Coffee }\end{array}$ & $\begin{array}{l}\text { Ground } \\
\text { Coffee }\end{array}$ & $\begin{array}{c}\text { Intense } \\
\text { Coffee }\end{array}$ \\
\hline \multicolumn{7}{|l|}{ PHENOLIC ACIDS } \\
\hline 3- $p$-Coumaroylquinic acid & 337 & 163 & & $X$ & $x$ & $x$ \\
\hline 4-p-Coumaroylquinic acid & 337 & $173,163,191$ & & $x$ & $x$ & $x$ \\
\hline 5- $p$-Coumaroylquinic acid & 337 & $191,173,163$ & & & & \\
\hline 3-feruloylquinic acid & 367 & 193,134 & & $X$ & $x$ & $x$ \\
\hline 4-feruloylquinic acid & 367 & 173,191 & & $x$ & $x$ & $x$ \\
\hline 5-feruloylquinic acid & 367 & 191 & & $X$ & $X$ & $x$ \\
\hline 3-Caffeoylquinic acid 1 & 353 & $179,191,173$ & & $x$ & $x$ & $x$ \\
\hline 3-Caffeoylquinic acid 2 & 353 & $179,191,173$ & & $x$ & $x$ & $x$ \\
\hline 4-Caffeoylquinic acid & 353 & 173,179 & & $X$ & $x$ & $x$ \\
\hline 5-Caffeoylquinic acid 1 & 353 & 191,179 & & $x$ & $x$ & $x$ \\
\hline 5-Caffeoylquinic acid 2 & 353 & 191,179 & & & $X$ & \\
\hline 5-Galloylquinic acid & 343 & $191,169,125$ & & & & \\
\hline Gallic acid & 169 & 125 & & & & \\
\hline Dicaffeoylquinic acid 1 & 515 & 353 & 179,191 & $X$ & $X$ & \\
\hline Dicaffeoylquinic acid 2 & 515 & 353 & 173,179 & $X$ & $X$ & $X$ \\
\hline Dicaffeoylquinic acid 3 & 515 & 353 & 179,191 & $x$ & $x$ & $x$ \\
\hline Dicaffeoylquinic acid 4 & 515 & 353 & 191,179 & $X$ & $x$ & $x$ \\
\hline Dicaffeoylquinic acid lactone & 335 & $161,137,179$ & & $x$ & $x$ & $x$ \\
\hline
\end{tabular}

\subsubsection{Tea}

In green and black teas, flavanols, flavonols, and phenolic acids were detected. In contrast, only flavonols and phenolic acids were present in mate tea, but flavanols were absent (Figure 2A, Tables 1 and 2). 
A

- $\mathrm{W}=\mathrm{M}=\mathrm{M}: \mathrm{W}$

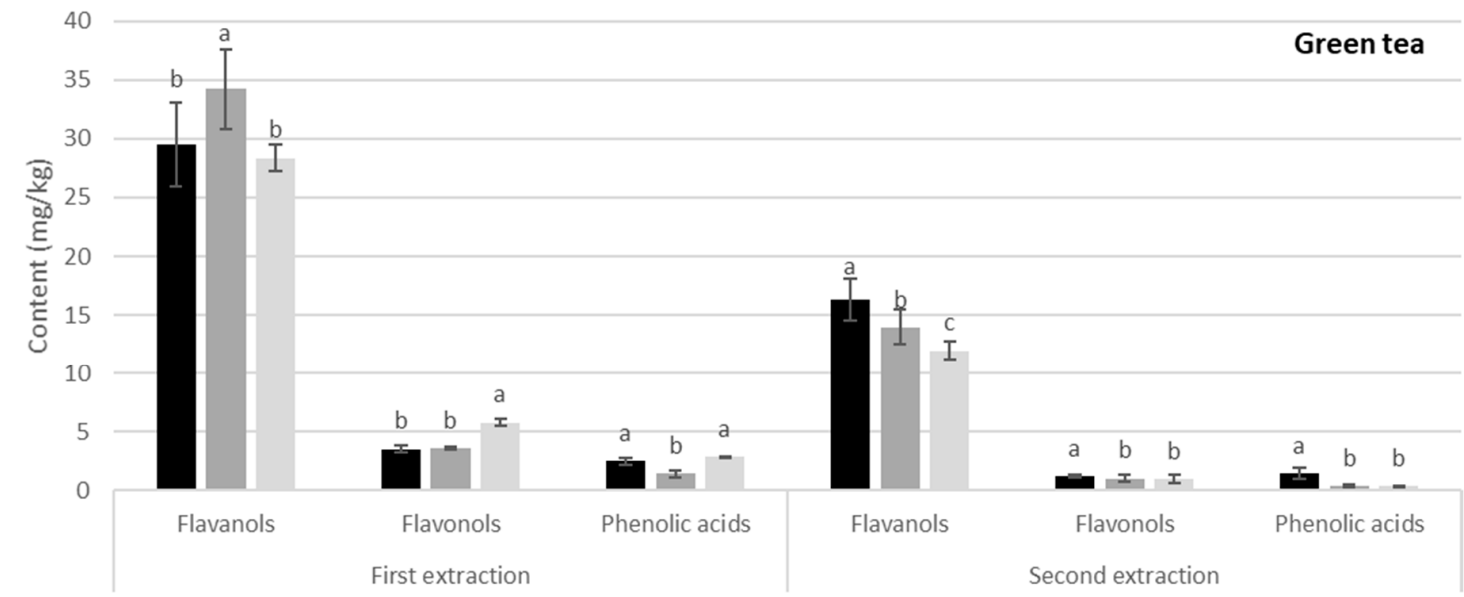

B

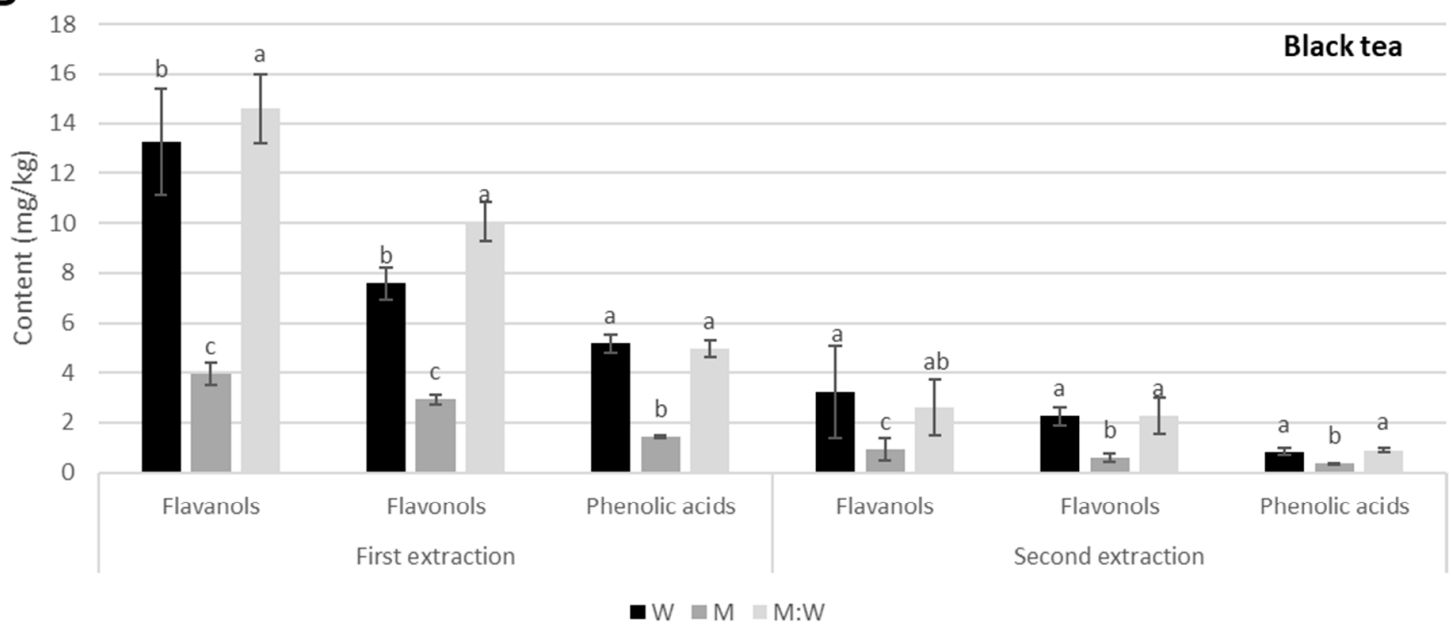

C

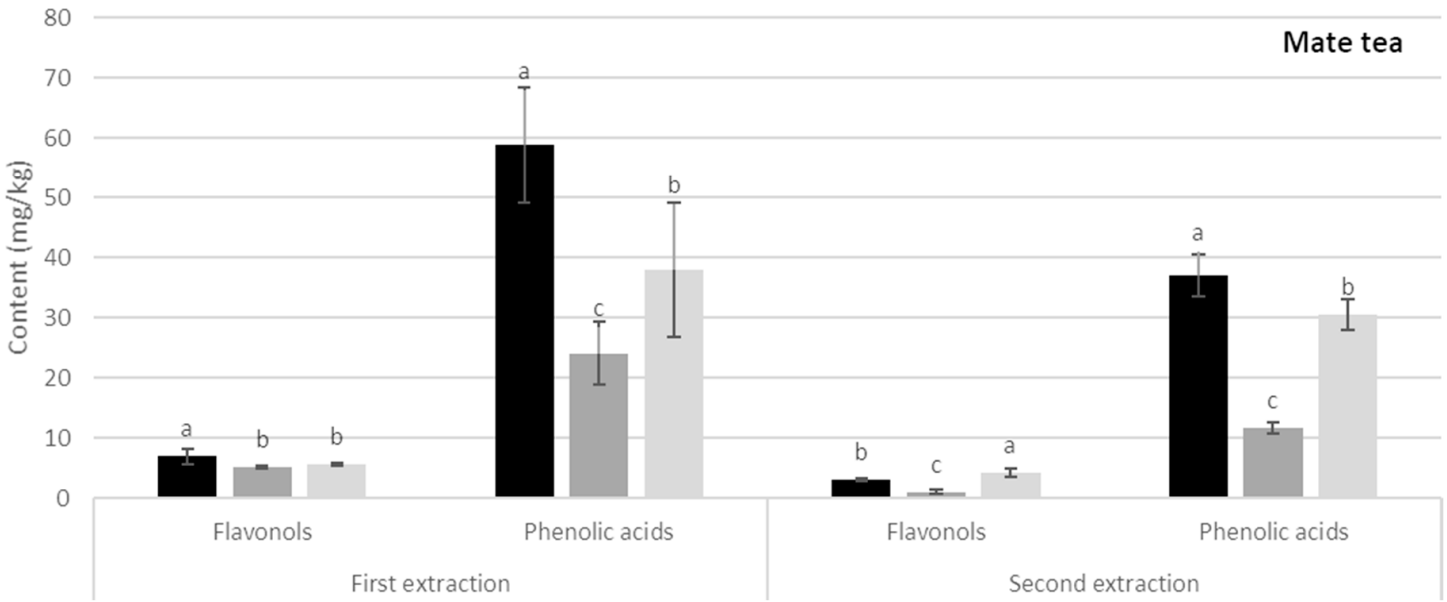

Figure 2. Phenolic content (mg/g) during first and second extraction with different solvents (W: water, M: 100\% methanol; W:M water:methanol mix) in commercial brands of (A) Green tea; (B) Black tea; (C) Mate tea. Different letters indicate statistical significance $(p \leq 0.05)$ in phenolic content between solvents. 
Green tea. Flavanols are the most abundant phenolic compounds in both first and second extraction with all solvents, cca. $30 \mathrm{mg} / \mathrm{kg}$ in the first extraction, and cca. $14 \mathrm{mg} / \mathrm{kg}$ in the second extraction, representing a $45-60 \%$ decrease. The highest amount was obtained with methanol in the first extraction, and with water in second extraction. The most abundant flavanol is a procyanidin dimer, followed by two different epigallocatechin gallates.

Flavonols and phenolic acids are much less abundant in both extractions and with all solvents, ranging between 0.3 and $5.8 \mathrm{mg} / \mathrm{kg}$, and decreasing by $70-80 \%$ between the first and second extraction. However, water was the best extraction solvent for phenolic acids in both extractions, and for flavonols in the second extraction. Among flavonols, the most abundant were quercetin hexoside rhamnoside hexoside and quercetin-3-rutinoside, while, among phenolic acids, it was 5-O-galloylquinic acid (Table S2).

Black tea. Contents of all phenolic groups in black tea were lower than green tea, and the same trend was observed among solvents (Figure 2B and Table S3). Flavanols are still more abundant than flavonols and phenolic acids in both extractions and for all solvents. However, methanol extracted significantly less flavanols than water and water:methanol mix in both extractions and for all phenolic groups. For the first extraction, there was $13.3 \mathrm{mg} / \mathrm{kg}$ for water, $4 \mathrm{mg} / \mathrm{kg}$ for methanol, and $14.6 \mathrm{mg} / \mathrm{kg}$ for water:methanol mix, with a decrease of $76-82 \%$ in the second extraction. The most abundant flavanols were epicatechin, gallocatechin, epigallocatechin gallate, and theaflavin, while catechin, epigallocatechin, epicatechin gallate, gallocatechin gallate, theaflavine-3,3'-digallate, and theaflavine-3-gallate showed lower amounts (Table S3).

Flavonols were less abundant than flavanols, being $7.6 \mathrm{mg} / \mathrm{kg}$ in water, $2.9 \mathrm{mg} / \mathrm{kg}$ in methanol, and $10.1 \mathrm{mg} / \mathrm{kg}$ in water:methanol mix. In the second extraction, they decreased by about $70 \%$ in water, and cca. $80 \%$ in methanol and water:methanol mix. The most abundant flavonols were quercetin-3-rutinoside, quercetin-3-galactoside, and quercetin-3-glucoside.

Phenolic acids showed the lowest content of the three phenolic groups, being $5.2 \mathrm{mg} / \mathrm{kg}$ in water, $1.4 \mathrm{mg} / \mathrm{kg}$ in methanol, and $5 \mathrm{mg} / \mathrm{kg}$ in water:methanol mix, decreasing by about $80 \%$ in second extraction. The most abundant phenolic acids were 4-caffeoylquinic acid and 4-coumaroylquinic acid (Table S3).

Mate tea. No flavanols were detected here (Figure 2C and Table S4). In contrast, the amounts of phenolic acids were significantly higher than those of flavonols, and also higher than all other phenolic groups in green and black tea, both in the first and second extractions and almost all solvents. The content was $58.8 \mathrm{mg} / \mathrm{kg}$ in water, $24.1 \mathrm{mg} / \mathrm{kg}$ in methanol, and $37.9 \mathrm{mg} / \mathrm{kg}$ in water:methanol mix, decreasing by $37 \%, 51 \%$, and $19 \%$, respectively, in the second extraction. The most abundant phenolic acids were 3-p-coumaroylquinic acid, 3-caffeoylquinic acid, 4-caffeoylquinic acid, and three different dicaffeoylquinic acids.

Flavonols showed similar amounts than black tea, $7 \mathrm{mg} / \mathrm{kg}$ with water, and cca. $5 \mathrm{mg} / \mathrm{kg}$ with methanol and water:methanol mix, decreasing by 56,79 , and $25 \%$, respectively, in the second extraction. The most abundant flavonol was quercetin-3-rutinoside.

\subsubsection{Coffee}

In all three kinds of coffees, only phenolic acids were detected (Figure 3). Contrary to most trends among teas, in all types of coffees and both extractions, the water:methanol mix was significantly the most efficient solvent. 


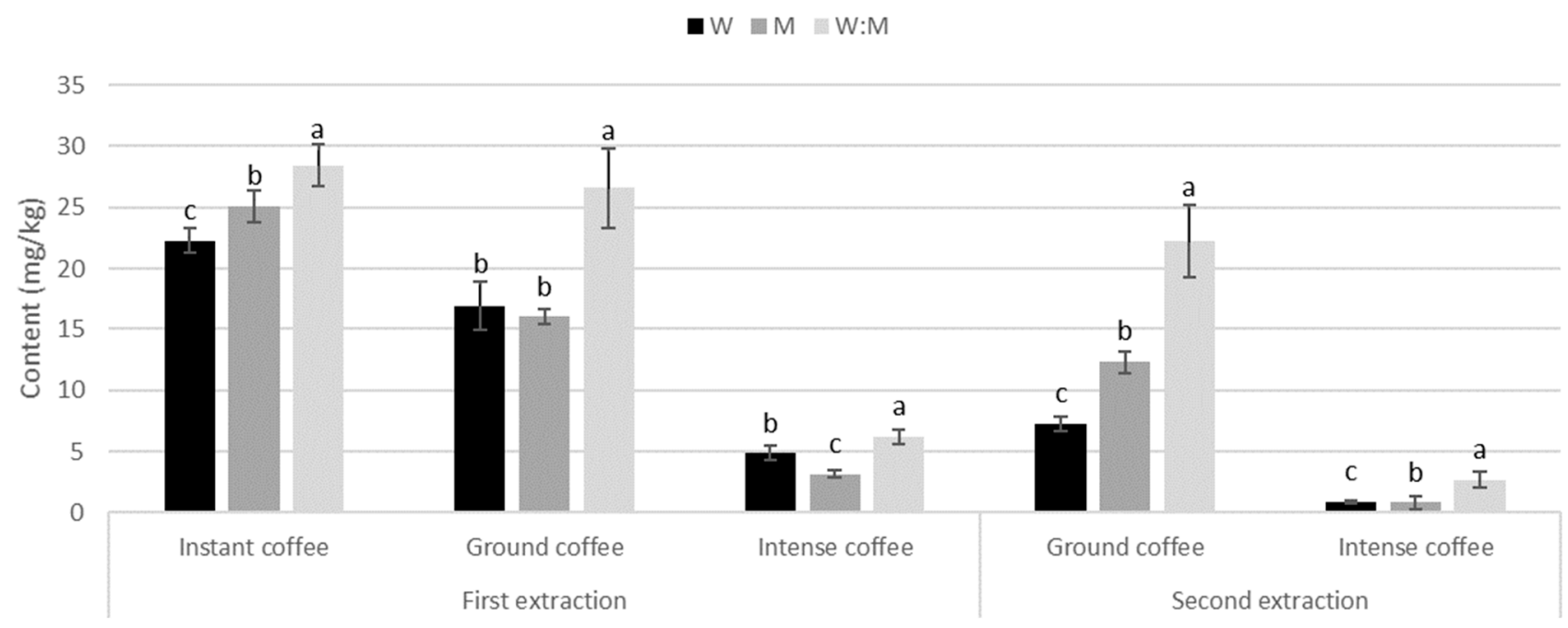

Figure 3. Phenolic acids content $(\mathrm{mg} / \mathrm{g})$ during first and second extraction with different solvents in different types of coffees. Different letters indicate statistical significance $(p \leq 0.05)$ in phenolic content between solvents.

Instant coffee. Phenolic acids were $22.3 \mathrm{mg} / \mathrm{kg}$ in water, $25 \mathrm{mg} / \mathrm{kg}$ in methanol, and $28.4 \mathrm{mg} / \mathrm{kg}$ in water:methanol mix during first extraction (Table S5). The most abundant phenolic acids were two different 3-caffeoylquinic acids, 4-caffeoylquinic acid, and 5caffeoylquinic acid.

Ground coffee. Phenolic acid content was cca. $16 \mathrm{mg} / \mathrm{kg}$ in water and methanol, and $26.6 \mathrm{mg} / \mathrm{kg}$ in water:methanol mix, decreasing by $57 \%$ in water, $23 \%$ in methanol, and $16 \%$ in water:methanol mix (Table S5). The most abundant phenolic acids were 3-caffeoylquinic acid, 4-caffeoylquinic acid, and 5-caffeoylquinic acid.

Intense coffee. It showed the lowest content of phenolic acids of all types of coffees and in all solvents. They were $4.8 \mathrm{mg} / \mathrm{kg}$ in water, $3.2 \mathrm{mg} / \mathrm{kg}$ in methanol, and $6.2 \mathrm{mg} / \mathrm{kg}$ in water:methanol mix, decreasing $82 \%, 74 \%$, and $57 \%$ in second extraction, respectively (Table S5). The most abundant phenolic acid was 3-caffeoylquinic acid.

\section{Discussion}

Caffeine and other phenolic compounds are all involved in plant defense mechanisms and are extracted by the same method. However, they are discussed separately, because there is some evidence in coffees that their concentrations are not necessarily related [29].

\subsection{Caffeine Content}

Regarding caffeine content, we found that, among all the beverages, it is the highest in instant coffee (regardless of the solvent) and black tea (in water and water:methanol mix extractions), which is consistent with previous reports [30,31]. The caffeine content in black tea reported to be similar to that of decaffeinated coffee, and it has been recommended as an adequate substitute for coffee in patients with limited caffeine intake [32]. Our results not only contradict this statement, as black tea contains similar amounts of caffeine that instant coffee, but also show that the caffeine content is higher than that of ground and intense coffee. In addition, instant coffee was reported to have lower caffeine content than green and black tea, but higher than mate tea [33]. However, since the results vary with extraction method, comparisons should be taken with caution, since the authors extracted with successive dilutions of methanol. Our results with $100 \%$ methanol showed that instant coffee has higher caffeine content than all teas, but with 50\% methanol, black tea showed the highest caffeine content.

Among coffee types, the highest caffeine content was observed in instant coffee, in contrast to other studies [34] in which ground coffee showed the highest caffeine content. Instant coffee showed an even higher caffeine content than coffees advertised as 'intense', 
suggesting higher caffeine amounts. It has also been observed in other coffees that caffeine amounts differ from the declared amounts [35]. However, the caffeine content is higher than that in coffee pulp, which is also used as fertilizer [36].

Green tea shows relatively high caffeine content in the first extraction, in some cases higher [30] and in others lower [37] than previously reported. However, the caffeine content of green tea was lower than black tea, in contrast with other publications, in which similar amounts were reported [38], or black tea showed higher amounts than green tea [37]. In agreement with our results, mate tea shows considerably lower caffeine content than black and green tea [33,39].

However, the main focus should be on the caffeine content in the second extraction because the aim is to find natural sources with potential use as pesticides, and the reuse of boiled tea bags or coffee grounds is the ideal source of plant defense compounds that could be easily extracted and used as pesticides in urban horticulture. With the exception of black tea, all sources show low caffeine content during the second extraction. For coffees, it has been described that the second extraction shows only $10 \%$ of the caffeine content in $50 \%$ ethanol and $80^{\circ} \mathrm{C}$ [40]. Since instant coffee shows the highest caffeine content at the first extraction, it would be suitable as a potential source of metabolites with pesticide activity, but it could not be a reusable source since no second extraction is possible. For all other coffees, as well as green tea and mate tea, the caffeine content is also very low at the second extraction. Thus, if they are to be used as pesticides, a larger number of tea bags would be needed to have any effect. The use of coffee grounds in agriculture has been extensively described and has shown that high doses of caffeine and phenolic compounds can also be phytotoxic $[21,41]$. However, content of caffeine and phenolic compounds in the second extraction is always more than 50\% lower, suggesting that the second extraction infusions could be used directly.

\subsection{Phenolic Profile}

Phenolic compounds are also known for their role in plant defense against pests and UV tolerance. Therefore, the evaluation of their content is crucial to provide the basis for a possible use of coffee or tea as a natural pesticide. In this case, the difference in trends of phenolic content between teas and coffees helps to decide between the two.

Several phenolic compounds have been described in coffee [42]. Among them, chlorogenic acid (5-caffeoylquinic acid or 5-CQA) is known for its antioxidant activity [43], and also for its antiviral and antifungal effect in animals and plants [44,45]. A similar phenolic profile has also been described in coffee pulp, although with a lower content [36]. It has been previously reported that 5-CQA is the most abundant phenolic compound in coffee, followed by 4-CQA and 3-CQA $[34,46,47]$. This is coincident with our results for ground coffee but not for instant and intense coffee, where 3-CQA predominates. Di-CQ lactone was also identified in coffee [46], as well as in our results.

Tea polyphenols find a variety of applications in the food, medical and pharmaceutical industries due to their multiple health benefits, including their antioxidant and antibacterial activities [48,49]. In tea, the main polyphenols are catechin derivatives, gallic acid, flavonols, and theaflavins [50,51]. This was also confirmed by our results, as flavanols were predominant, except for mate tea, where no flavanols were present.

In particular, black tea has been described as a rich source of catechin derivatives [37,52], which is in agreement with our results, as its derivatives (epicatechin, epigallocatechin, gallocatechin, and epigallocatechin gallate) showed the highest amounts. Moreover, it was reported that gallic acid is the major phenolic compound in black tea $[33,50]$, but, in our results, gallic acid was not even detected.

In green tea, epicatechin derivatives are the main compounds [33,53]. Although our results show that some epicatechin derivatives show the highest amounts among phenolic compounds, procyanidins and some phenolic acids also show comparable amounts. Catechin derivatives are responsible for the bitterness and astringency of green tea [54]. 
Their abundancy in green tea makes this source suitable as a pesticide, as it could act as a repellent against pests.

Our results related to flavonols and phenolic acids in green, black, and mate tea are also coincident with those previously reported, with quercetin-3-rutinoside and chlorogenic acid being the most abundant [37].

\subsection{Solvents}

Regarding solvents, in most cases, the highest caffeine amount was obtained during water extractions. It is known that caffeine is soluble in water and increases with temperature, since alkaloids are typically associated in complexes with organic acids, which enhance their solubility. In agreement with our results, solubility of pure caffeine in methanol is significantly lower than in water [55].

All tested solvents are not toxic to plants, with the exception of $100 \%$ methanol. In particular, the toxic effect of methanol was tested on tobacco (Nicotiana tabacum L.), tomato (Solanum lycopersicum L.), and arabidopsis (Arabidopsis thaliana (L.) Heynh.), both in foliar and root applications. However, lower concentrations of methanol have a positive effect on growth in tomato, wheat, and other species [56].

It was reported [40] that the extraction of caffeine in methanol was higher than in water at room temperature, but almost equal at higher temperatures. However, our results show that methanol extracted less caffeine at room temperature in all sources.

In the case of water:methanol mix, the extraction of phenolic compounds was higher than water [25]. Our results show that, for caffeine, the water:methanol mix extracts similar amounts as water. However, for flavanols, flavanols, and phenolic acids, the water:methanol mix extracted a higher content of phenolic compounds in coffee and black tea, but not in green and mate tea. It has been reported that a $70 \%$ methanol enhanced polyphenol extraction in tea [57], but in our results, no or very little difference with water extractions was observed, although 50\% methanol extracted higher amounts of polyphenols than $100 \%$ methanol.

\section{Conclusions}

The problem of food waste is being addressed globally as the environmental footprint of urbanization increases and resource efficient use is recommended to increase sustainability. This is particularly important in urban or semi-urban settlements where recycling of organic matter is difficult at both macro- and micro- levels, not only because of the high amounts and low availability of disposal areas, but also because the concept of reuse is not natural to citizens. Therefore, we would achieve a solution to this problem not only by reducing food waste, but also by reusing it.

Coffee and tea are popular beverages worldwide, and therefore generate large amounts of waste. To address this problem, the reuse of tea bags and coffee grounds could be an interesting option, as they not only detoxify grounds, but also could be used as pesticides, at least for domestic use. Although the first extraction was far more efficient than the second, green tea also showed a high content of flavanols in the second extraction, as well as mate tea for phenolic acids. Black tea could also be a good choice as the caffeine content is highest in both extractions. With these results, the customer could ingest the desired caffeine intake and still obtain a high amount of caffeine in reused coffee ground to use it as pesticides in urban horticulture. However, the phenolic compounds in black tea are very low in the second extraction. Therefore, further analysis should be carried out to evaluate the effect of these compounds as pesticides. In most cases, water was the most efficient solvent for the extraction of phenolic compounds and caffeine, which represents a great advantage for urban horticulture, since it is a simple extraction method from an easily accessible source. 
Supplementary Materials: The following are available online at https: / www.mdpi.com/article/ 10.3390/horticulturae7110443/s1, Table S1: Caffeine content (mean \pm SE, in mg/g) and decrease (\%) in coffees and teas during successive extractions with different solvents (W: water; M: methanol; W:M water: methanol mix). Different letters indicate statistical significance $(p \leq 0.05)$ in caffeine content between solvents. Table S2: Phenolic compounds content (mean $\pm \mathrm{SE}$, in $\mathrm{mg} / \mathrm{kg}$ ) and decrease (\%) in green tea during successive extractions with different solvents (W: water, $\mathrm{M}$ : methanol; $\mathrm{W}: \mathrm{M}$ water: methanol mix). Different letters indicate statistical significance $(p \leq 0.05)$ in phenolic content between solvents. Table S3: Phenolic compounds content (mean \pm SE, in $\mathrm{mg} / \mathrm{kg}$ ) and decrease (\%) in black tea during successive extractions with different solvents (W: water, M: methanol; W:M water: methanol mix). Different letters indicate statistical significance $(p \leq 0.05)$ in phenolic content between solvents. Table S4: Phenolic compounds content (mean $\pm \mathrm{SE}$, in $\mathrm{mg} / \mathrm{kg}$ ) and decrease $(\%)$ in mate tea during successive extractions with different solvents (W: water, M: methanol; W:M water: methanol mix). Different letters indicate statistical significance $(p \leq 0.05)$ in phenolic content between solvents. Table S5: Phenolic acids content (mean $\pm \mathrm{SE}$, in $\mathrm{mg} / \mathrm{kg}$ ) and decrease $(\%)$ in coffees during successive extractions with different solvents (W: water, M: methanol; W:M water: methanol mix). Different letters indicate statistical significance $(p \leq 0.05)$ in phenolic content between solvents.

Author Contributions: Conceptualization, M.M.P.; Formal analysis, B.G., M.M.P. and R.V.; Funding acquisition, M.H. and R.V.; Investigation, B.G.; Methodology, M.M.P. and R.V.; Project administration, M.H. and R.V.; Resources, M.H. and R.V.; Supervision, M.M.P., M.H. and R.V.; Validation, M.M.P. and R.V.; Visualization, M.C.G.; Writing—original draft, M.C.G.; Writing—review and editing, M.C.G., M.M.P., M.H. and R.V. All authors have read and agreed to the published version of the manuscript.

Funding: This study is part of program P4-0013-0481, which is funded by the Slovenian Research Agency (ARRS).

Institutional Review Board Statement: Not applicable.

Informed Consent Statement: Not applicable.

Data Availability Statement: Most data presented in this study are available in Supplementary Material. The remaining data are available on request from the corresponding author.

Conflicts of Interest: The authors declare no conflict of interest.

\section{References}

1. Minatel, I.O.; Borges, C.V.; Ferreira, M.I.; Gomez, H.A.G.; Chen, C.-Y.O.; Lima, G.P.P. Phenolic compounds: Functional properties, impact of processing and bioavailability. Phenolic Compd. Biol. Act. 2017, 8, 1-24.

2. Khan, M.; Liu, H.; Wang, J.; Sun, B. Inhibitory effect of phenolic compounds and plant extracts on the formation of advance glycation end products: A comprehensive review. Food Res. Int. 2020, 130, 108933. [CrossRef] [PubMed]

3. Medic, A.; Solar, A.; Hudina, M.; Veberic, R. Phenolic Response to Walnut Anthracnose (Ophiognomonia leptostyla) Infection in Different Parts of Juglans regia Husks, Using HPLC-MS/MS. Agriculture 2021, 11, 659. [CrossRef]

4. Mencin, M.; Abramovič, H.; Jamnik, P.; Mikulič Petkovšek, M.; Veberič, R.; Terpinc, P. Abiotic stress combinations improve the phenolics profiles and activities of extractable and bound antioxidants from germinated spelt (Triticum spelta L.) seeds. Food Chem. 2021, 344, 128704. [CrossRef]

5. Zamljen, T.; Medič, A.; Veberič, R.; Hudina, M.; Štampar, F.; Slatnar, A. Apple Fruit (Malus domestica Borkh.) Metabolic Response to Infestation by Invasive Brown Marmorated Stink Bug (Halyomorpha halys Stal.). Horticulturae 2021, 7, 212. [CrossRef]

6. Anaya, A.L.; Cruz-Ortega, R.; Waller, G.R. Metabolism and ecology of purine alkaloids. Front. Biosci. 2006, 11, 2354-2370. [CrossRef]

7. Filho, O.G.; Mazzafera, P. Caffeine Does Not Protect Coffee Against the Leaf Miner Perileucoptera coffeella. J. Chem. Ecol. 2000, 26, 1447-1464. [CrossRef]

8. Hollingsworth, R.G.; Armstrong, J.W.; Campbell, E. Caffeine as a repellent for slugs and snails. Nature 2002, 417, 915-916. [CrossRef]

9. Mohanpuria, P.; Kumar, V.; Yadav, S.K. Tea caffeine: Metabolism, functions, and reduction strategies. Food Sci. Biotechnol. 2010, 19, 275-287. [CrossRef]

10. Mostakim, M.; Khan, A.R. Effect of coffee on the growth and development of the red flour beetle, Tribolium castaneum (Herbst) (Coleoptera: Tenebrionidae. Bangladesh J. Zool. 2015, 42, 211-216. [CrossRef]

11. Kim, Y.-S.; Uefuji, H.; Ogita, S.; Sano, H. Transgenic tobacco plants producing caffeine: A potential new strategy for insect pest control. Transgenic Res. 2006, 15, 667-672. [CrossRef] [PubMed]

12. Peneva, A. Allelopathic Effect of Seed Extracts and Powder of Coffee (Coffea Arabica L.) on Common Cocklebur Xanthium strumarium L. Bulg. J. Agric. Sci. 2007, 13, 205. 
13. Smyth, D.A. Effect of methylxanthine treatment on rice seedling growth. J. Plant Growth Regul. 1992, 11, 125-128. [CrossRef]

14. Mohanpuria, P.; Yadav, S.K. Retardation in seedling growth and induction of early senescence in plants upon caffeine exposure is related to its negative effect on Rubisco. Photosynthetica 2009, 47, 293-297. [CrossRef]

15. Heck, C.I.; De Mejia, E.G. Yerba Mate Tea (Ilex paraguariensis): A Comprehensive Review on Chemistry, Health Implications, and Technological Considerations. J. Food Sci. 2007, 72, R138-R151. [CrossRef] [PubMed]

16. McCusker, R.R.; Goldberger, B.A.; Cone, E.J. Caffeine Content of Specialty Coffees. J. Anal. Toxicol. 2003, 27, 520-522. [CrossRef]

17. Schmeda-Hirschmann, G.; Quispe, C.; González, B. Phenolic Profiling of the South American "Baylahuen” Tea (Haplopappus spp., Asteraceae) by HPLC-DAD-ESI-MS. Molecules 2015, 20, 913. [CrossRef]

18. Kelebek, H. LC-DAD-ESI-MS/MS characterization of phenolic constituents in Turkish black tea: Effect of infusion time and temperature. Food Chem. 2016, 204, 227-238. [CrossRef]

19. Tungmunnithum, D.; Thongboonyou, A.; Pholboon, A.; Yangsabai, A. Flavonoids and Other Phenolic Compounds from Medicinal Plants for Pharmaceutical and Medical Aspects: An Overview. Medicines 2018, 5, 93. [CrossRef] [PubMed]

20. Hoornweg, D.; Bhada-Tata, P. What a Waste: A Global Review of Solid Waste Management; World Bank: Washington, DC, USA, 2012; p. 98.

21. Sanchez-Hernandez, J.C.; Domínguez, J. Chapter 12-Vermicompost Derived from Spent Coffee Grounds: Assessing the Potential for Enzymatic Bioremediation; Galanakis, C.E., Ed.; Academic Press: Cambridge, MA, USA, 2017; pp. 369-398. ISBN 978-0-12-811290-8.

22. Guo, S.; Kumar Awasthi, M.; Wang, Y.; Xu, P. Current understanding in conversion and application of tea waste biomass: A review. Bioresour. Technol. 2021, 338, 125530. [CrossRef]

23. Holmberg, T.; Ideland, M. The circular economy of food waste: Transforming waste to energy through 'make-up' work. J. Mater. Cult. 2021, 26, 344-361. [CrossRef]

24. Lakatos, E.S.; Yong, G.; Szilagyi, A.; Clinci, D.S.; Georgescu, L.; Iticescu, C.; Cioca, L.-I. Conceptualizing Core Aspects on Circular Economy in Cities. Sustainability 2021, 13, 7549. [CrossRef]

25. Mussatto, S.I.; Ballesteros, L.F.; Martins, S.; Teixeira, J.A. Extraction of antioxidant phenolic compounds from spent coffee grounds. Sep. Purif. Technol. 2011, 83, 173-179. [CrossRef]

26. Nour, V.; Stampar, F.; Veberic, R.; Jakopic, J. Anthocyanins profile, total phenolics and antioxidant activity of black currant ethanolic extracts as influenced by genotype and ethanol concentration. Food Chem. 2013, 141, 961-966. [CrossRef]

27. Wang, S.Y.; Zheng, W.; Galletta, G.J. Cultural system affects fruit quality and antioxidant capacity in strawberries. J. Agric. Food Chem. 2002, 50, 6534-6542. [CrossRef]

28. Mikulic-Petkovsek, M.; Rescic, J.; Schmitzer, V.; Stampar, F.; Slatnar, A.; Koron, D.; Veberic, R. Changes in fruit quality parameters of four Ribes species during ripening. Food Chem. 2015, 173, 363-374. [CrossRef]

29. Bobková, A.; Jakabová, S.; Belej, L'.; Jurčaga, L.; Čapla, J.; Bobko, M.; Demianová, A. Analysis of caffeine and chlorogenic acids content regarding the preparation method of coffee beverage. Int. J. Food Eng. 2021, 17, 403-410. [CrossRef]

30. Mumin, A.; Akhter, K.F.; Abedin, Z.; Hossain, Z. Determination and characterization of caffeine in tea, coffee and soft drinks by solid phase extraction and high performance liquid chromatography (SPE-HPLC). Malays. J. Chem. 2006, 8, 45-51.

31. Vignoli, J.A.; Bassoli, D.G.; Benassi, M.T. Antioxidant activity, polyphenols, caffeine and melanoidins in soluble coffee: The influence of processing conditions and raw material. Food Chem. 2011, 124, 863-868. [CrossRef]

32. Poroch-Serițan, M.; Michitiuc, C.B.; Jarcău, M. Studies and research on caffeine content of various products. BRAIN. Broad Res. Artif. Intell. Neurosci. 2018, 9, 29-35.

33. Rostagno, M.A.; Manchón, N.; D’Arrigo, M.; Guillamón, E.; Villares, A.; García-Lafuente, A.; Ramos, A.; Martínez, J.A. Fast and simultaneous determination of phenolic compounds and caffeine in teas, mate, instant coffee, soft drink and energetic drink by high-performance liquid chromatography using a fused-core column. Anal. Chim. Acta 2011, 685, 204-211. [CrossRef] [PubMed]

34. Jeon, J.-S.; Kim, H.-T.; Jeong, I.-H.; Hong, S.-R.; Oh, M.-S.; Yoon, M.-H.; Shim, J.-H.; Jeong, J.H.; Abd El-Aty, A.M. Contents of chlorogenic acids and caffeine in various coffee-related products. J. Adv. Res. 2019, 17, 85-94. [CrossRef]

35. Desbrow, B.; Hall, S.; Irwin, C. Caffeine content of Nespresso ${ }^{\circledR}$ pod coffee. Nutr. Health 2018, 25, 3-7. [CrossRef] [PubMed]

36. da Silveira, J.S.; Mertz, C.; Morel, G.; Lacour, S.; Belleville, M.-P.; Durand, N.; Dornier, M. Alcoholic fermentation as a potential tool for coffee pulp detoxification and reuse: Analysis of phenolic composition and caffeine content by HPLC-DAD-MS/MS. Food Chem. 2020, 319, 126600. [CrossRef] [PubMed]

37. Faria, C.B.; Prado, J.M.; Rostagno, M.A.; Schmidt, F.L.; Meireles, M.A.A. Chapter 8 Simultaneous Determination of Caffeine and Phenolic Compounds in Tea and Coffee. In Caffeine: Chemistry; The Royal Society of Chemistry: London, UK, 2012 ; pp. 130-153. ISBN 978-1-84973-367-0.

38. Musilová, A.; Kubíčková, A. Effect of brewing conditions on caffeine content in tea infusions simulating home-made cup of tea. Mon. Für Chem.-Chem. Mon. 2018, 149, 1561-1566. [CrossRef]

39. Tfouni, S.A.V.; Camara, M.M.; Kamikata, K.; Gomes, F.M.L.; Furlani, R.P.Z. Caffeine in teas: Levels, transference to infusion and estimated intake. Food Sci. Technol. 2018, 38, 661-666. [CrossRef]

40. Bi, W.; Zhou, J.; Row, K.H. Decaffeination of coffee bean waste by solid-liquid extraction. Korean J. Chem. Eng. 2011, 28, 221-224. [CrossRef]

41. Hardgrove, S.J.; Livesley, S.J. Applying spent coffee grounds directly to urban agriculture soils greatly reduces plant growth. Urban For. Urban Green. 2016, 18, 1-8. [CrossRef] 
42. Nuhu, A.A. Bioactive Micronutrients in Coffee: Recent Analytical Approaches for Characterization and Quantification. ISRN Nutr. 2014, 2014, 1-13. [CrossRef]

43. Hoelzl, C.; Knasmüller, S.; Wagner, K.-H.; Elbling, L.; Huber, W.; Kager, N.; Ferk, F.; Ehrlich, V.; Nersesyan, A.; Neubauer, O.; et al. Instant coffee with high chlorogenic acid levels protects humans against oxidative damage of macromolecules. Mol. Nutr. Food Res. 2010, 54, 1722-1733. [CrossRef] [PubMed]

44. Urushisaki, T.; Takemura, T.; Tazawa, S.; Fukuoka, M.; Hosokawa-Muto, J.; Araki, Y.; Kuwata, K. Caffeoylquinic Acids Are Major Constituents with Potent Anti-Influenza Effects in Brazilian Green Propolis Water Extract. Evid.-Based Complement. Altern. Med. 2011, 2011, 254914. [CrossRef]

45. Villarino, M.; Sandín-España, P.; Melgarejo, P.; De Cal, A. High Chlorogenic and Neochlorogenic Acid Levels in Immature Peaches Reduce Monilinia laxa Infection by Interfering with Fungal Melanin Biosynthesis. J. Agric. Food Chem. 2011, 59, $3205-3213$. [CrossRef] [PubMed]

46. Perrone, D.; Farah, A.; Donangelo, C.M.; de Paulis, T.; Martin, P.R. Comprehensive analysis of major and minor chlorogenic acids and lactones in economically relevant Brazilian coffee cultivars. Food Chem. 2008, 106, 859-867. [CrossRef]

47. Jeon, J.-S.; Kim, H.-T.; Jeong, I.-H.; Hong, S.-R.; Oh, M.-S.; Park, K.-H.; Shim, J.-H.; Abd El-Aty, A.M. Determination of chlorogenic acids and caffeine in homemade brewed coffee prepared under various conditions. J. Chromatogr. B 2017, 1064, 115-123. [CrossRef] [PubMed]

48. Koch, W.; Zagórska, J.; Marzec, Z.; Kukula-Koch, W. Applications of Tea (Camellia sinensis) and Its Active Constituents in Cosmetics. Molecules 2019, 24, 4277. [CrossRef] [PubMed]

49. Ceylan, M.M.; Bulut, M.; Alwazeer, D. Improvement of pasting and textural properties of sunn-damaged wheat flour using tea waste extracts. J. Food Process. Preserv. 2021, 45, e15728. [CrossRef]

50. Li, S.; Lo, C.-Y.; Pan, M.-H.; Lai, C.-S.; Ho, C.-T. Black tea: Chemical analysis and stability. Food Funct. 2013, 4, 10-18. [CrossRef]

51. Rad, A.H.; Fathipour, R.B.; Azizi, A.; Bidgoli, F.K. Application of Tea Extract in Food Industry. Curr. Nutr. Food Sci. 2020, 16, 998-1004. [CrossRef]

52. Bhandari, K.; De, B.; Goswami, T.K. Evidence based seasonal variances in catechin and caffeine content of tea. SN Appl. Sci. 2019, 1, 1-6. [CrossRef]

53. Mukhtar, H.; Ahmad, N. Tea polyphenols: Prevention of cancer and optimizing health. Am. J. Clin. Nutr. 2000, 71, 1698S-1702S. [CrossRef] [PubMed]

54. Liang, Y.; Lu, J.; Shang, S. Effect of Gibberellins on Chemical Composition and Quality of Tea (Camellia sinensis L). J. Sci. Food Agric. 1996, 72, 411-414. [CrossRef]

55. Shalmashi, A.; Golmohammad, F. Solubility of caffeine in water, ethyl acetate, ethanol, carbon tetrachloride, methanol, chloroform, dichloromethane, and acetone between 298 and 323 K. Lat. Am. Appl. Res. 2010, 40, 283.

56. Ramírez, I.; Dorta, F.; Espinoza, V.; Jiménez, E.; Mercado, A.; Peña-Cortés, H. Effects of Foliar and Root Applications of Methanol on the Growth of Arabidopsis, Tobacco, and Tomato Plants. J. Plant Growth Regul. 2006, 25, 30-44. [CrossRef]

57. Pasrija, D.; Anandharamakrishnan, C. Techniques for Extraction of Green Tea Polyphenols: A Review. Food Bioprocess Technol. 2015, 8, 935-950. [CrossRef] 